\title{
Vulnerable personality profile in patients with chronic pain: Relationship with coping, quality of life and adaptation to disease
}

\author{
Perfil de personalidad vulnerable en pacientes con dolor crónico: \\ relación con el afrontamiento, la calidad de vida y la adaptación a la \\ enfermedad
}

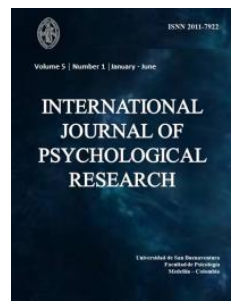

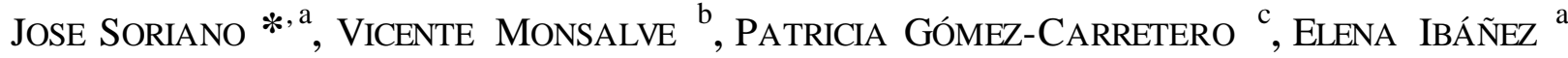 \\ ${ }^{a}$ University of Valencia, España \\ ${ }^{\mathrm{b}}$ Valencia General University Hospital, España \\ ${ }^{\mathrm{c}}$ Foundation for Pain Study and Management of Valencia, España
}

\begin{abstract}
In this study with a sample of chronic pain patient, personality profiles defined as the individual's scores on all five dimensions (NEO-FFI) are used, to establish relations with coping, quality of life, and adaptation to disease. After a cluster analysis two groups have been obtained: the first one being a trend to intermediate scores in all five dimensions and characterized by moderate neuroticism, average extraversion, low openness, moderate agreeableness, and moderate conscientiousness, whereas the second one is characterized by traits of vulnerability determined by high neuroticism, low extraversion, low openness, moderate agreeableness and low conscientiousness. Significant univariate differences are seen between both groups in the use of coping strategies (CAD-R), quality of life (SF-36), and adaptation to disease (LI). In addition, multivariate differences are seen in coping and quality of life.
\end{abstract}

Key Words: Personality, Big Five, Coping, Quality of Life, Chronic Pain.

\section{RESUMEN}

En este estudio realizado con pacientes diagnosticados con dolor crónico se emplean perfiles de personalidad entendidos como la puntuación de los individuos en cinco dimensiones (NEO-FFI) para relacionarlos con el afrontamiento, la calidad de vida y la adaptación a la enfermedad. Tras la aplicación de un análisis cluster, se obtienen dos grupos: uno con tendencia hacia puntuaciones intermedias en las cinco dimensiones caracterizado por moderado Neuroticismo, media Extraversión, baja Apertura, moderada Amabilidad y moderada Responsabilidad; el segundo grupo se caracteriza por poseer características de vulnerabilidad determinadas por alto Neuroticismo, baja Extraversión, baja Apertura, moderada Amabilidad y baja Responsabilidad. Entre los dos grupos aparecen diferencias significativas univariadas en el uso de estrategias de afrontamiento (CAD-R), calidad de vida (SF-36) y adaptación a la enfermedad (LI). También aparecen diferencias multivariadas en afrontamiento y calidad de vida.

Palabras Clave: Personalidad, Big Five, Estilos de Afrontamiento, Calidad de Vida, Dolor Crónico.

\section{* Correspondence / Correspondencia:}

José Soriano Pastor, Departamento. Personalidad, Evaluación y T. Psicológicos, Facultad de Psicología,Universidad de Valencia, Avda. Blasco Ibáñez, 21. 46010 Valencia, España, E-mail: jose.f.soriano@uv.es

\section{Indexing / indexaciones}

International Journal of Psychological Research se encuentra incluida en: Scopus, EBSCO (Academic Search Complete), Dialnet, Imbiomed, Doaj, Scirus, New Jour, Ulrichsweb, Pserinfo, Journal Seek, Google scholar. 


\section{INTRODUCTION}

Since the 1980s, interest has grown in studying the importance of coping strategies for adaptation to disease, particularly chronic disease. Outcomes have been interpreted primarily based on the transactional model put forward by the group of Lazarus and Folkman (1984). Based on the premises proposed by Suls, Davis and Harvey (1996), this theoretical model would correspond to the so-called "second approach to the study of coping strategies", whereby personality variables are of little relevance to determining the use of such strategies. These authors believe that we are now entering a "third generation", focusing on the big five personality traits to explain the use of coping strategies and adaptation to stress.

A basic assumption is that traits are stable across the time showing few variations in his average scoring evaluated across diverse questionnaires (Conly, 1984; Costa \& McCrae, 1998). The classifications of the Trait Psychology have established at present a generally accepted model of Personality, derived from the lexical analysis, called Five Factor Model, in which big five dimensions are outlined: Neuroticism (N), Extraversion (E), Openness to experience (O), Agreeableness (A) and Conscientiousness (C) (Costa \& McCrae, 1998).

All big five personality factors are related to one another, as had been put forward by Digman (1997). Therefore, the existence of two superordinate factors was taken into account: a so-called "beta" factor characterized by low $\mathrm{N}$, high $\mathrm{E}$, moderate $\mathrm{O}$, and moderate $\mathrm{C}$, and an "alpha" factor characterized by moderate $\mathrm{N}$, low A, and low C (Blackburn, Renwick, Donnelly, \& Logan, 2004). Without the intention to replicate this two-factor approach, but considering that all five dimensions are interrelated (Egan, Deary, \& Austin, 2000), we aimed to assess the influence of personality on coping and health by assessing not only each individual dimension but all of them simultaneously, which allows us to obtain personality profiles and establish degrees of adaptiveness (in terms of coping and QoL) to chronic pain. Some of these aspects have been assessed before with positive results: a resilient personality profile has been identified as opposed to a profile that is vulnerable to stress (Campbell-Sills, Cohan, \& Stein, 2006; Soriano, Monsalve, Ibáñez, y GómezCarretero, 2010).

Studies have aimed to establish correlations between the big five personality traits and appraisal, coping and quality of life (QoL) (Atkinson \& Violato, 1994; Connor-Smith \& Flachsbart, 2007). It has been observed that variables such as neuroticism (Lauver \& Johnson, 1997), extraversion (Phillips \& Gatchel, 2000), or optimism correlate to variables such as coping and QoL (Garofalo, 2000). The results of these studies suggest that extraversion and optimism act as resistance factors, whereas neuroticism seems to act as a factor of risk or vulnerability. From this point of view, personality is a predictor of appraisal, coping and health outcomes (described in terms of QoL) in a range of stressful situations (O'Brien \& DeLongis, 1996). Nevertheless, the existence of a "personality pattern" prone to the development of chronic pain illness has not been proven.

However, recent studies in chronic pain patients (Ramírez, López, \& Esteve, 2004; Soriano, et al., 2010) have demonstrated that the contribution of personality dimensions to explaining their impact on coping strategies is relatively scarce. A reason behind this may be that these studies have not assessed the effect of potential mediator variables, such as appraisal. Another aspect to consider is the design of these studies, in which the contribution of each variable was assessed separately, i.e. correlations were explored specifically between individual dimensions to coping strategies and their impact on quality of life.

In this way, coping has been revealed as one of the most important concepts since the $80 \mathrm{~s}$ in the psychology of health (Ibáñez \& Soriano, 2008). In recent years, in the case of chronic pain, relationship between coping, personality and quality of life has been widely studied (see a review in Soriano and Monsalve, 2005). In general, the strategies shown as "passive" (religion, acceptance, catharsis, etc.) have been linked with worse fit to the disease, while the so-called active (search for information, active coping, etc.), have been linked inversely (Jensen, Turner, Roman, \& Karoly, 1991), acting first ones as predictors of future dysfunction (Boothby, Thorn, Stroud, \& Jensen, 1999).

Relationships between personality and coping has also been studied (Connor-Smith, Compas, Wadsworth, Thomsen, \& Saltzman, 2000; Jang, Thordarson, Stein, Cohan, \& Taylor, 2007; Penley \& Tomaka, 2002), noting that the $\mathrm{N}$ dimension acts as a factor of vulnerability to stress and $\mathrm{E}, \mathrm{C}$ and $\mathrm{O}$, as protective factors, being a the dimension that contributes least to relations with coping. In the case of chronic pain, these results have also been confirmed (Soriano et al., 2010), showing that an alternative to the bivariate work can be multivariate, through the use of profiles in all dimensions. The results are derived from previous studies where this type of profiles are found (Campbell-Sills, et al., 2006). In chronic diseases and, specifically, in chronic pain, QoL is one of the criteria used, nowadays, to assess the efficacy of work performed in pain therapy units. The treatment of pain, though not always successful, attempts to maintain the patient's QoL; for this reason, QoL is a very important element to determine whether a patient can deal with pain well or not. The results show that certain coping strategies account for different aspects of the chronic pain patients' quality of life (Lamé, Peters, Vlaeyen, Kleef, \& Patijn, 2005). Nevertheless, the relationships existing among personality, coping and health in the context of chronic pain remain unclear and studies yield contradictory results (Weisberg \& Keefe, 1999). 
Adaptation to pain has been evaluated in several studies through the Lattinen Index (IL) (Monsalve, Soriano, \& de Andrés, 2006), which has also been used as a measure of the intensity of pain and as an index of adjustment in the perception of pain, interacting positively with the visual analogue scale of pain (VAS) and with worse quality of life, as well as passive coping strategies (Monsalve, et al., 2006; Sriwatanakul, Kelvie, \& Lasagna, 1983), however there are no studies that relate it to the patient's personality dimensions.

In other way, some authors (Jensen et al.; MeyerRosenberg, Burckhardt, Huizar, Kvarnström, \& Nord, 2001) suggest that results of studies may be influenced by different types of pain, but this question has not been confirmed in another studies, in there are scare differences referred to pain (Monsalve, et al., 2006; Soriano, Monsalve y Gómez-Carretero, 2007). In this sense somatic pain was defined as pain affecting the skin, muscles, joints or ligaments. Somatic pain is well-localized and is characterized by sensations reported to be deep, oppressive, burning or stabbing. On the other hand, neuropathic pain usually results from damage in the central or peripheral nervous system. Neuropathic pain is characterized by its spontaneous onset and a lowered pain threshold to low-intensity stimuli (such as rubbing the skin). It is usually described as superficial, sharp and electrical (Bonica, 1990).

Something similar happens related with the differences between sex/gender and age, where differences are only shown in the use of the strategy of coping with information search appear only in males (11,91 male vs 10,21 female), but there is no difference in quality of life, or in VAS. However, related with the age also differences are shown both in the use of strategies of coping in favour of the younger, in adaptation (level of activity, Ll) and only a few on quality of life (physical function, SF-36) (Monsalve et al., 2006).

The objective of this study is to determine if the use of personality profiles may be useful for determining the adjustment of patients of chronic pain, understood in terms of coping, adaptation and quality of life. We try to support the usefulness of determining personality profiles and their impact on coping and quality of life in patients with chronic pain.

\section{METHOD}

\section{Participants}

A total of 296 patients diagnosed of chronic pain began participation in this study.

Inclusion criteria were as follows:

1. Patients referred for chronic pain treatment for the first time.
2. Patients diagnosed with a chronic pain syndrome according to the IASP criteria (Mersdey \& Bogduk, 1994).

3. Patients meeting the duration criterion of minimum 3 months' history of the syndrome.

4. Patients not suffering from any psychiatric disease according to the DSM IV TR (American Psychiatry Association, 2000).

5. Patients $\geq 18$ years of age.

6. Patients who agree to take part in the study (sign the informed consent form).

Exclusion criteria were as follows:

1. Patients with prior treatment for chronic pain.

2. Patients who follow psychiatric or psychological therapy.

3. Patients with cognitive limitation to answer to the psychometric tests.

\section{Measures}

$V A S$ : The perceived severity of pain was assessed using a visual analog scale (Huskisson, 1983). Subjects were asked to assess the severity of their usual pain by making a vertical mark on a 10-centimeter line limited by two points, an initial (0) point of no pain and a final (10) point of maximum pain. The score is derived by measuring the distance from the initial point to the vertical mark on the line.

NEO Five Factor Inventory (NEO-FFI) (Costa \& McCrae, 2002). The NEO-FFI is a 60-item self-report measure of the big five dimensions of personality measuring neuroticism $(N)$, extraversion $(E)$, openness to experience $(O)$, agreeableness $(A)$, and conscientiousness $(C)$. Respondents rate each item on a five-point scale from "strongly disagree" to "strongly agree". The alphas ranged from $0.72(A)$ to $0.87(E)$, indicating acceptable reliabilities.

Pain Coping Questionnaire (CAD-R) (Soriano \& Monsalve, 2004). The CAD-R (Spanish acronym for Cuestionario de afrontamiento del dolor) is a 24-item coping inventory with 6 scales for the following coping strategies: distraction, search for information, religion, catharsis, mental self-control, and self-assertion. Each scale comprises four items. The CAD-R has two higher order subscales known as "active coping" and "passive coping". The active coping subscale comprises the distraction, search for information, mental self-control, and self-assertion strategies (alpha $=0.83$ ). The passive coping subscale comprises the religion and catharsis strategies (alpha $=0.82$ ). Patients indicate how much they have used each strategy specifically to cope with pain, on a five-point scale from 0 (never) to 4 (always). The alphas ranged from 0.66 (distraction) to 0.94 (religion). 
Lattinen Index (LI). This short instrument consists of only 6 items which in turn encompass 6 dimensions of the chronic pain patient each (Vas, Perea, Méndez, Martín, $\&$ Pons, 2005). These dimensions are: severity of pain, level of activity, frequency of pain, use of analgesics, nighttime sleep quality, and number of sleep hours of the patient. The score for each item is given on a 4-point scale ranging from the lowest incidence to the greatest severity or disruption. The LI has been validated on a Spanish sample of patients with chronic pain (Monsalve et al., 2006).

$S F-36$. Is a general health survey. It was designed by Ware \& Sherbourne (1992) as a result of the Medical Outcome Study (MOS) protocol. In later studies, the SF-36 has demonstrated its psychometric properties for different groups of patients (McHorney, Ware, \& Raczek, 1993; McHorney, Ware, Lu, \& Sherbourne, 1994). The SF-36 has been validated in a Spanish sample (Alonso et al., 1998). The SF-36 comprises 36 items and 8 scales: Physical functioning (interference in physical activities such as self-care, walking, etc.), role-physical (problems with work or other daily activities), bodily pain (severity of pain and its effect on daily activities), general health (self-ass essment of current and future health and resistance to disease), vitality (feeling full of energy versus feeling tired), social functioning (interference with normal social activities due to health problems), role-emotional (problems with work or other daily activities as a result of emotional problems), and mental health (depression, anxiety, behavioral and emotional control). Even though the SF-36 was initially designed for an assessment of the patient's general health status, it has been used as a quality of life endpoint in healthcare (Aaronson et al., 1992; Bullinger et al., 1998), and in the setting of chronic pain (Angst, Verra, Lehmann, \& Aeschlimann, 2008). The alphas ranged from 0.64 (general health) to 0.86 (social functioning).

\section{Procedure}

Sample was recruited in a consecutive case series of 296 patients presenting for the first time at the Multidisciplinary Unit for Pain Treatment of the University General Hospital Consortium (Consorcio Hospital General Universitario) of Valencia, Spain, were asked to participate in the study. Following an evaluation by the medical team in charge of diagnosing the pain syndrome, and after signing the relevant informed consent form, patients were assessed at the Psychology Office of the Unit, where demographic data were collected and a psychometric assessment was performed using the measuring instruments defined below.

The diagnoses of the different chronic pain syndromes were established by the medical staff at the Pain Therapy Unit, following the IASP criteria through a clinical interview and a review of the relevant diagnostic tests (International Ass ociation for Study of Pain, 1994).

The following analyses were undertaken in this descriptive study: mean differences between different types of pain (Student t-test), correlation analysis (Pearson) among all five personality dimensions and the remaining socio-demographic, coping and QoL variables, cluster analysis (k-means) to obtain the subjects' personality profiles and finally a stepwise discriminant analysis including the groups obtained in the cluster analysis as the criterion variable and the 6 coping strategies, the 8 QoL dimensions, the $6 \mathrm{LI}$ variables and VAS score as the predictor variables. Data were processed using the statistical package SPSS.17.

\section{RESULTS}

\section{Sample characteristics}

The analyzed sample had a mean age of 51.62 years ( $S D=12.56$; range, 21 to 82 years), and $57.8 \%$ were females $(n=171)$. The educational level of the patients was distributed as follows: $1.7 \% \quad(n=5)$ were illiterate, $9.1 \%$ $(n=27)$ could read and write, $55.7 \% \quad(n=165)$ had completed their primary education, $13.2 \% \quad(n=39)$ had vocational education, $12.5 \% \quad(n=37)$ had completed secondary education, and $7.8 \%(n=23)$ had attained higher education. Additionally, $89.5 \% \quad(n=265)$ lived in company and $96.3 \%(n=222)$ had a Catholic background; however, only $41.9 \%$ claimed to practice their religion $(n=124)$

Regarding the type of pain, 75.7\% $(n=224)$ had neuropathic pain, and $24.3 \%(n=72)$ had somatic pain.

\section{Summary statistics}

Based on the centiles established in the NEO-FFI manual (Costa \& McCrae, 2002), the results indicate that the sample (with no gender differences) scores very high on neuroticism $(\mathrm{N}=27.6$; centile $=95)$, very low on extraversion $(\mathrm{E}=24.8$; centile $=10)$, very low on openness to experience $(\mathrm{O}=23.6$; centile $=22)$, high on agreeableness $(A=36$; centile $=75)$, and low on conscientiousness $(C=34.6$; centile $=29)$. Table I summarizes the mean scores and SD for all study variables.

\section{Pain differences}

The study sample was divided into groups based on type of pain (224 patients with neuropathic pain, and 72 patients with somatic pain). All the study variables were compared among pain type groups (socio-demographic characteristics, LI, coping, quality of life and personality). 
Table 1. Mean, S.D., Pearson correlation matrix: personality, quality of life and coping

\begin{tabular}{|c|c|c|c|c|c|c|c|}
\hline & Mean & $\mathrm{sd}$ & Neurot. & Extrav. & Open. & Agreea. & Conscient. \\
\hline Neuroticism & 27.56 & 10.56 & & & & & \\
\hline Extraversion & 44.81 & 10.85 & $-.55^{* *}$ & & & & \\
\hline Openness & 23.61 & 8.38 & $-.174 * *$ & $.436 * *$ & & & \\
\hline Agreeableness & 36.03 & 6.96 & $-.247 * *$ & $.151 * *$ & .046 & & \\
\hline Conscientiousness & 34.61 & 7.68 & $-.401 * *$ & $.392 * *$ & $.198 * *$ & $.303 * *$ & \\
\hline Age & 51.62 & 12.57 & $-.168^{* *}$ & .029 & -.114 & $.198 * *$ & $.187 * *$ \\
\hline Educational level & 3.49 & 1.12 & -.037 & $.134 *$ & $.312 * *$ & -.105 & -.086 \\
\hline Severity of pain & 3.14 & .63 & $.182 * *$ & $-.166^{* *}$ & .093 & .097 & -.031 \\
\hline Level of activity & 2.20 & .72 & $.142 *$ & $-.118 *$ & -.053 & .051 & -.034 \\
\hline Frequency of pain & 3.75 & .66 & $.140^{*}$ & -.056 & .048 & .064 & .013 \\
\hline Use of analgesics & 2.00 & .41 & $.194 * *$ & $-.173 * *$ & -.056 & -.067 & $-.117 *$ \\
\hline Nighttime sleep quality & 3.01 & 1.30 & $.260 * *$ & $-.254 * *$ & -.070 & $.120^{*}$ & -.020 \\
\hline Sleep hours & 6.13 & 1.90 & -.097 & .053 & -.004 & .085 & $-.134 *$ \\
\hline VAS & 8.07 & 1.49 & $.233 * *$ & $-.178 * *$ & .040 & $.133^{*}$ & -.015 \\
\hline Phy sical functioning & 33.19 & 23.15 & $-.189 * *$ & $.196 * *$ & .037 & -.076 & .049 \\
\hline Role-phy sical & 12.41 & 24.18 & $-.243^{* *}$ & $.193 * *$ & -.079 & .046 & $.142 *$ \\
\hline Bodily pain & 22.55 & 18.19 & $-.298 * *$ & $.272 * *$ & -.044 & .048 & $.201 * *$ \\
\hline General health & 33.88 & 18.49 & $-.513^{* *}$ & $.458 * *$ & $.120 *$ & .057 & $.231 * *$ \\
\hline Vitality & 29.40 & 23.87 & $-.459 * *$ & $.466 * *$ & $.114 *$ & -.026 & $.224 * *$ \\
\hline Social functioning & 45.74 & 31.34 & $-.523^{* *}$ & $.528 * *$ & $.131 *$ & .042 & $.228 * *$ \\
\hline Role-emotional & 33.89 & 41.93 & $-.491 * *$ & $.390 * *$ & $.119 *$ & .109 & $.200 * *$ \\
\hline Mental health & 44.17 & 25.01 & $-.743^{* *}$ & $.538 * *$ & $.200 * *$ & $.144^{*}$ & $.286 * *$ \\
\hline Distraction & 10.79 & 3.87 & -.102 & $.179 * *$ & $.410 * *$ & $.200 * *$ & $.187 * *$ \\
\hline Search For Information & 11.69 & 4.09 & .041 & .013 & $.133^{*}$ & .021 & .067 \\
\hline Religion & 9.44 & 5.52 & $.195^{* *}$ & -.111 & -.034 & $.206 * *$ & .050 \\
\hline Catharsis & 11.01 & 3.86 & .064 & .071 & .062 & .052 & .064 \\
\hline Mental Self-Control & 9.68 & 5.04 & .102 & -.021 & $.132 *$ & -.064 & $.127 *$ \\
\hline Self-Assertion & 15.61 & 3.65 & $-.269 * *$ & $.272 * *$ & $.340 * *$ & $.155^{* *}$ & $.263 * *$ \\
\hline Passive Strategies & 10.22 & 3.64 & $.181 * *$ & -.047 & .007 & $.184 * *$ & .072 \\
\hline Active Strategies & 11.94 & 2.77 & -.062 & $.147 *$ & $.363^{* *}$ & .100 & $.234 * *$ \\
\hline
\end{tabular}

Differences were found in only 4 variables. Group of patients with neuropathic pain scores lower on 3 of these variables: age (50.74 vs. $54.35 ; p=.034)$, performance status (2.14 vs. 2.39; $p=.012)$ and sleep quality (2.91 vs. $3.31 ; p=.025)$. Compared to patients with somatic pain, patients with neuropathic pain only score higher on the physical functioning QoL variable (35.29 vs. 26.66, $p=.006$ ). This indicates that patients with neuropathic pain are somewhat younger and have better performance status, better sleep quality and better quality of life in terms of performing their activities of daily living, such as washing self, moving around, etc. 


\section{Bivariates}

A correlation analysis was performed to establish the association between each personality dimension and the remaining variables. The results are summarized in Table I. From a socio-demographic standpoint, older ages correlate to lower $\mathrm{N}$ and higher $\mathrm{A}$ and $\mathrm{C}$. In addition, there is a positive association between $\mathrm{O}$ and educational level, which is not surprising, as the openness dimension has been associated to education and intelligence (Goldberg, 1990)

As for personality dimensions, $\mathrm{N}$ correlates to several $\mathrm{LI}$ variables and acts as an element of interference with QoL in all the dimensions obtained on the SF-36 questionnaire. For coping strategies, the $\mathrm{N}$ dimension correlates to religion and low self-assertion, as well as to a greater use of passive strategies. On the other hand, E appears to have the opposite effect of $\mathrm{N}$, with lower scores on the LI variables and better QoL in all scales. Distraction and self-assertion are the coping strategies that are positively correlated to this dimension.

The $\mathrm{O}$ dimension does not correlate to the $\mathrm{LI}$ variables and correlates poorly to QoL aspects. However, $\mathrm{O}$ is the dimension that shows the strongest correlation to both first-order and second-order active coping strategies.

The A dimension does not correlate to quality of life or LI but correlates to passive and some active coping strategies. Finally, the C dimension correlates to QoL and to active coping strategies.

If personality dimensions had to be classified, it could be argued that neuroticism predisposes the individual to poorer adaptation to disease; extraversion and, to a lesser extent, conscientiousness and openness are protecting dimensions; and agreeableness correlates the least with disease.

\section{Cluster analysis and differences between groups}

After the hierarchical cluster analysis (intra-group method) was performed, a dendrogram was obtained showing two groups. From this result, a cluster analysis was undertaken (k-means method) by selecting these 2 groups to obtain the best classification of individuals according to personality traits based on the NEO-FFI scores. The results of the final clusters can be found on Table 2.

The group comprising cluster 1 scored lower on neuroticism and higher on extraversion, openness, agreeableness, and conscientiousness compared to the group comprising cluster 2. Based on the scores established in the NEO-FFI manual (Costa \& McCrae, 2002), the results indicate that the group 2 (without gender distinctions) scores very high on neuroticism (centile $=98$ ), very low on extraversion (centile $=1)$, very low on openness (centile $=10$ ), moderate on agreeableness (centile $=60$ ) and very low on conscientiousness (centile=18). The group 1 scores high on neuroticism (centile $=71$ ), moderate on extraversion (centile $=51$, moderately low on openness (centile $=35$ ), high on agreeableness (centile $=76$ ), and moderate on conscientiousness (centile $=57$ ).

Table 2. Cluster analysis. Cores of final clusters. ANOVA

\begin{tabular}{lcccc}
\hline & Cluster 1 & Cluster 2 & F & Sig. \\
\hline Neuroticism & 19.71 & 34.91 & 312.904 & .000 \\
Extraversion & 33.14 & 17.04 & 361.417 & .000 \\
Openness & 27.08 & 20.38 & 55.950 & .000 \\
Agreeableness & 37.57 & 34.60 & 14.070 & .000 \\
Conscientiousness & 37.58 & 31.84 & 47.792 & .000 \\
\hline$N$ & 143 & 153 & & \\
\hline
\end{tabular}

No statistically significant socio-demographic differences were found between the groups (age and cultural level). Both groups were compared for LI, VAS, QoL and coping strategies.

Based on the LI and compared to group 1, group 2 showed greater pain severity $(M=3.22$; group $1 M=3.06$, $\mathrm{t}=-2.257, p=0.025)$, poorer performance status $(M=2.29$; group $1 M=2.10, \mathrm{t}=-2.254, p=0.025)$, greater analgesic use $(M=2.07$; group $1 M=1.92, \mathrm{t}=-3.043, p=0.003)$, and poorer sleep quality $(M=3.32 ;$ group $1 \quad M=2.67, \quad \mathrm{t}=-4.427$, $p=0.000$ ).

Group 2 scored higher on the VAS $(M=8.29$, group $1 M=7.85, \mathrm{t}=-2.549, p=0.011)$. Additionally, group 2 exhibited poorer quality of life on total of the 8 scores: Physical function $(M=30.26$; group $1 M=36.32, \mathrm{t}=2.269$, $p=0.024)$ role-physical $(M=6.53$, group $1 \quad M=18.7$, $\mathrm{t}=4.464, \quad p=0.000)$, bodily pain $(M=18.39$, group 1 $M=26.99, \mathrm{t}=4.171, \quad p=0.000)$, general health $(M=26.01$, group $1 M=42.3, \mathrm{t}=8.424, \quad p=0.000)$, vitality $(M=19.9$, group $1 M=39.58, \mathrm{t}=7.764, p=0.000)$, social functioning $(M=30.21$, group $1 M=62.36, \mathrm{t}=10.259, p=0.000)$, roleemotional $(M=15.9$, group $1 M=53.14, \mathrm{t}=8.509, p=0.000)$, and mental health $(M=29.54$, group $1 M=59.83$, $\mathrm{t}=8.509$, $p=0.000$ ). Finally, when considering the coping strategies used, the vulnerable group made less frequent use of distraction $\quad(M=10.14$, group $1 \quad M=11.48, \quad \mathrm{t}=3.025$, $p=0.003)$, religion $(M=10.09$, group $1 M=8.76, \mathrm{t}=2.079$, $p=0.039), \quad$ self-assertion $\quad(M=14.5$, group $1 \quad M=16.8$, $\mathrm{t}=5.694, p=0.000)$ and active coping strategies $(M=11.51$, group $1 M=12.40, \mathrm{t}=2.784, p=0.006$ )

\section{Discriminant analysis}

In order to establish the multivariate discrimination potential between the two personality profiles resulting from the cluster analysis (on all five NEO-FFI factors), a discriminant analysis was undertaken including the two groups as criterion measures — resilient (group 1) versus 
vulnerable (group 2) - and the VAS score, the LI variables, the coping strategies and quality of life as the predictor variables. Using a stepwise procedure (Wilks' lambda method; $\mathrm{F}$ to enter $=3.84$ and $\mathrm{F}$ to remove=2.71), canonical correlation of $\mathrm{r}=.680$, eigenvalue $=.861$, and a Wilks' lambda value $=.537(p=.000)$ were obtained. These results indicate acceptable discrimination, as groups do not overlap excessively. Variables included in the analysis are five aspects of quality of life (physical functioning, general health, social functioning, role-emotional and mental health) and one coping strategy (self-assertion). This function shows an allocation of individuals to groups of $76.2 \%$ in group 1 and $88.9 \%$ in group 2. Results are shown in table 3 .

Table 3. Discriminant analysis

\section{Standardized coefficients of canonical discriminant function}

\begin{tabular}{lr}
\hline & \multicolumn{2}{c}{ Function } \\
\cline { 2 - 2 } & \multicolumn{1}{c}{1} \\
\hline Physical functioning & -.249 \\
General health & .306 \\
Social function & .388 \\
Role-emotional & .213 \\
Mental health & .475 \\
Self assertion & .333 \\
\hline
\end{tabular}

Classification(a)

\begin{tabular}{lllrrr}
\hline & & $\begin{array}{l}\text { Initial cases } \\
\text { number }\end{array}$ & \multicolumn{2}{c}{$\begin{array}{c}\text { Predicted } \\
\text { group }\end{array}$} & Total \\
\hline Original & Cases & & 1 & \multicolumn{1}{c}{2} & \multicolumn{1}{c}{1} \\
& number & 1 & 109 & 34 & 143 \\
& & 2 & 17 & 136 & 153 \\
& $\%$ & 1 & 76,2 & 23,8 & 100,0 \\
& 2 & 11,1 & 88,9 & 100,0
\end{tabular}

A Correctly classified $82.8 \%$ of original grouped cases.

\section{DISCUSSION}

In this study, we propose that applying personality profiles could be more useful than exploring individual bivariate associations between personality dimensions and health related quality of life and coping variables. As explained above, our sample included 296 patients with two types of pain: 224 patients with neuropathic pain and 72 patients with somatic pain. Both types of pain have been compared to determine whether they could be influenced by their different pain characteristics as had been suggested by some authors (Jensen et al., 1991). In the neuropathic pain group, patients are somewhat younger and show greater independence and self-sufficiency in their activities of daily living, as well as greater sleep quality; it is not surprising that younger patients would show responses of this kind. Interestingly, no differences were observed in the personality dimensions or the use of coping strategies, which suggests that the type of pain is not a differential variable. Some of these aspects have been observed already in previous studies (Soriano et al., 2007).

The associations between personality and coping have been widely studied in the literature (Connor-Smith \& Flachsbart, 2007), pointing to a low to moderate effect between these spheres; in this regard, an association of $r=.3$ is considered to be satisfactory (Suls et al., 1996). This has led to the assumption that personality may have indirect effects on variables such as coping or quality of life, promoting behaviors which may ultimately impact the implementation of more adaptive behaviors. Nonetheless, the as sociations identified between personality and coping are usually based on dispositional measures of coping, which do not reflect the transactional nature of stress and coping (Connor-Smith \& Flachsbart, 2007). Retrospective reports are most common, and these are in turn biased by the personality features of the subjects (Schwartz, Neale, Marco, Shiffman, \& Stone, 1999).

In order to determine to which degree each personality dimension individually may be considered to be a protection or vulnerability agent for the sample used in this study, a correlation (bivariate) analysis was performed focusing on the associations between the five personality dimensions and their correlations to the coping strategies used, adaptation to disease, and quality of life.

Considering the as sociations between the patients personality traits and their adaptation to disease symptoms, it should be emphasized that $\mathrm{N}$ acts as a risk factor, as it correlates positively to all the LI variables and to the VAS and negatively to QoL variables, which indicates low scores. The opposite is seen for E, which appears to act as a protective dimension. These results have been proposed by several previous studies (Lauver \& Johnson, 1997; Phillips \& Gatchel, 2000; Soriano \& Monsalve, 2002; Soriano \& Monsalve, 2004; Monsalve et al., 2006). Although less consistently, the $\mathrm{C}$ dimension also acts as a protective factor, correlating with better quality of life and better adaptation to pain as well as to more adaptive strategies, possibly because of its associations with high self-efficacy and the use of problem-driven strategies (Campbell-Sills et al., 2006). The $\mathrm{O}$ dimension shows lower yet positive correlations to quality of life but, interestingly, it correlates to adaptive coping strategies for chronic pain, such as distraction and self-assertion, possibly because of its search-foralternatives component and its ability to explore negative emotions and divert attention from the problem (ConnorSmith, et al., 2000; Jang, et al., 2007). The A dimension 
has the fewest significant correlations with no associations with QoL and only some with coping strategies of distraction, religion, self-assertion and passive strategies; this may be accounted for by stoicism and the ability to accept any type of coping strategy (Costa, Somerfield \& McCrae, 1996). There is no doubt that $\mathrm{A}$ is the poorest predictor for both coping and the results obtained (Penley \& Tomaka, 2002).

In order to work with personality profiles rather than separate dimensions, a cluster analys is was performed to categorize subjects into two groups: one group showing moderately high scores for $\mathrm{N}$ and $\mathrm{A}$, moderate scores for $\mathrm{E}$ and $\mathrm{C}$, and low scores for $\mathrm{O}$, which can be called resilient ("relatively adapted") group, and another group showing very high scores for $\mathrm{N}$, very low scores for $\mathrm{E}, \mathrm{O}$ and $\mathrm{C}$, and moderate scores for $\mathrm{A}$, which can be called the "vulnerable" group. This classification and the group names are taken from previous studies in which the NEOFFI was used to establish associations to resilience and a correlation was found between low $\mathrm{N}$ scores and high $\mathrm{E}$ and $\mathrm{C}$ scores to high resilience scores (Campbell-Sills et al., 2006; Soriano et al., 2010). Group 2 (vulnerable) is identified with the higher-order factor on the NEO-FFI as suggested by Egan et al. (2000) yet with opposite scores; this is referred to as the factor of non-psychopathological characteristics and is characterized by low N, high $\mathrm{E}$, high A, and high C. In our study we obtained the opposite scores, with group 2 (vulnerable) showing poorer scores in adaptation to disease and poorer quality of life in all scales of the SF-36 questionnaire, using more maladaptive coping strategies. In this regard, the high $\mathrm{N}$ score correlated to vulnerability; however, a low N score does not guarantee positive adaptation to adverse situations. The E dimension reflects positive affect, ability for interpersonal relationships, and social interaction, which is associated to resilience by the wide range of actions deployed to deal with stress (Tugade \& Fredrickson, 2004). It is considered that a high $\mathrm{C}$ score may involve reasoned implementation of the strategies to follow rather than the immediate use of problem-driven strategies (Skodol, 2010). On the other hand, A correlates to primary control strategies (instrumental social support) and $\mathrm{O}$ correlates to secondary control strategies such as distraction and cognitive restructuring (Connor-Smith \& Flachs bart, 2007).

Probably, the most clearly demarcated group in terms of personality dimensions is group 2 (vulnerable), which reflects the conditions of risk or lack of protection. Group 1 is not clearly resilient given its scores. Comparatively, however, group 1 shows much higher scores in quality of life and adaptation to disease.

Current theories often conceptualize resilience on a continuum with vulnerability, implying resistance to mental illness; however, this may not involve total lack of vulnerability to the development of psychiatric disorders (Ingram \& Price, 2001). These aspects have led us to consider our sample of chronic pain patients as little resilient patients, the results being consistent with previous studies in which chronic pain patients scored high on both anxiety and depression (Soucase, Soriano, y Monsalve, 2005).

Finally, the discriminant analysis shows to which extent these two personality profiles may characterize or differentiate the patients' behaviors from a multivariate perspective. Our results suggest that there is a clear difference in several aspects of quality of life and adaptation to pain, especially from a psychological and emotional perspective, in which the role of mental health should be emphasized as the most important element, followed by social relationships, general health and emotional role. Of note, the physical mobility aspect acts as a somewhat negative factor, i.e. discriminating for lower values. This is one of the few differences between both types of pain and may result from the lifestyles of patients in either group, an aspect which has not been assessed in this study.

In addition, it should be stated that the coping strategy discriminating between the two personality profiles has been reported to be the most adaptive strategy in previous studies, i.e. self-assertion (Soriano \& Monsalve, 2004; Soriano et al., 2010).

The influence of personality traits on pain and quality of life seems fairly clear. When we established clusters classified by their personality dimensions, we observed that all personality dimensions are good discriminators for selecting the clusters. Based on these clusters, differences were seen in terms of pain, quality of life and coping strategies, which points to the importance of these dimensions.

Neuroticism, extraversion and, to a lesser extent, conscientiousness are the primary dimensions, in terms of prediction, accounting for quality of life in patients with chronic pain. Interestingly, there are coping strategies that act as potential modulators of QoL, together with personality dimensions.

These results do not point to the existence of a personality profile of patients with chronic pain. However, they do prove the importance of personality dimensions on coping and quality of life. May be that facets of personality would be more useful in determining QoL, but this suppose more items in evaluate personality (Marrero, 2011). On the one hand, therefore, these results warrant further research of the role of personality variables on chronic pain; and, on the other hand, they underscore the need to consider personality in the assessment of patients with chronic pain in the setting of healthcare, not only from a psychopathological perspective, but also as a predictive criterion for coping and QoL, which is the ultimate objective of multidisciplinary interventions in the treatment of chronic pain. 


\section{REFERENCES}

Aaronson, N. K., Acquadro, C., Alonso, J., Apolone, G., Bucquet, D., Bullinger, M., ... Ware, J. E. Jr (1992). International Quality of Life Assessment (IQOLA) Project. Quality of Life Research, 1, 34951.

Alonso, J., Regidor, E., Barrio, G., Prieto, L., Rodríguez, C., y De la Fuente, L. (1998). Valores poblacionales de referencia de la versión española del Cuestionario de Salud SF-36. Medicina Clínica, 111, 410-416.

American Psychiatry Association. (2002). Manual Diagnóstico y Estadístico de los Trastornos Mentales: DSM-IV-TR. Barcelona: Masson.

Angst, F., Verra, M. L., Lehmann, S., \& Aeschlimann, A. (2008). Responsiveness of five condition-specific and generic outcome assessment instruments for chronic pain. BMC Medical Research Methodoogyl, $25,8-26$.

Atkinson, M. \& Violato, C. (1994). Neuroticism and coping with anger: the transsituational consistency of coping responses. Personality and Individual Differences, 17, 769-782.

Blackburn, R., Renwick, S., Donnelly, J., \& Logan, C. (2004). Big Five or Big Two? Superordinate factors in the NEO Five Factor Inventory and the Antisocial Personality Questionnaire. Personality and Individual Differences, 37, 957-970.

Bonica, J. J. (1990). Definitions and taxonomy of pain. In: J. J. Bonica (Ed.), The Management of Pain. ( $2^{\mathrm{a}} \mathrm{Ed}$. Vol. 1.). (pp. 18-27). New York: Lea \& Febiger.

Boothby, J., Thorn, B., Stroud, M., \& Jensen, M. (1999): Coping with pain. En R. Gatchel \& D. Turk (Eds.), Psychosocial factor in pain. Critical perspectives (pp. 343-359). New York. Guilford.

Bullinger, M., Alonso, J., Apolone, G., Leplège, A., Sullivan, M., Wood-Dauphinee, S., ... Ware, J. E. Jr. (1998). Translating health status questionnaires and evaluating their quality: The International Quality of Life Assessment Project approach. Journal of Clinical Epidemiology, 51(11), 913-923.

Campbell-Sills, L., Cohan, S., \& Stein, M. (2006). Relationship of resilience to personality, coping, and psychiatric symptoms in young adults. Behaviour Research and Therapy, 44, 585-599.

Conley, J. (1984). Longitudinal consistency of adult personality: self-reported psychological characteristics across 45 years. Journal of Personality and Social Psychology, 47, 1325-1333.

Connor-Smith, J., Compas, B., Wadsworth, M., Thomsen, A., \& Saltzman, H. (2000). Responses to stress in adolescence: Measurement of coping and involuntary stress responses. Journal of Consulting and Clinical Psychology, 68, 976-992.

Connor-Smith, J. \& Flachsbart, C. (2007). Relations between personality and coping: a meta-analysis. Journal of Personality and Social Psychology, 93, 1080-1107.
Costa, P. \& McCrae, R. (1998). Trait theories of personality. In: Barone, D., Hersen, V. \& Van Hasselt (Ed.), Advances in Personality (pp. 103121). New York: Plenum Press.

Costa, P. \& McCrae, R. (2002). NEO PI-R, Inventario de Personalidad NEO Revisado y NEO-FFI, Inventario NEO reducido de Cinco Factores. Madrid: TEA Ediciones.

Costa, P., Somerfield, M., \& McCrae, R. (1996). Personality and coping: A reconceptualization. In: M. Zeidner \& N. Endler (Ed.), Handbook of coping: Theory, research, applications (pp. 44-61). New York: Wiley.

Digman, J. (1997). Higher-order factors of the big five. Journal of Personality and Social Psychology, 73, 1246-1256.

Egan, V., Deary, I., \& Austin, E. (2000). The NEO-FFI: emerging British norms and item-level analysis suggest $\mathrm{N}, \mathrm{A}$, and $\mathrm{C}$ are more reliable than $\mathrm{O}$ and $\mathrm{E}$. Personality and Individual Differences, 29, 907-920.

Garofalo, J. (2000): Perceived optimism and chronic pain. In: R. Gatchel \& J. Weisberg (Ed.), Personality characteristics of patients with pain (pp. 203-217). London: British Library.

Goldberg, L. (1990). An alternative description of personality: The Big Five factor structure. Journal of Personality and Social Psychology, 59, 1216-1229.

Huskisson, E. (1983). Visual Analogue Scales. In: R. Melzack (Ed.), Pain Measurement and Assessment (pp. 33-37). New York: Raven.

Ibáñez, E. \& Soriano, J. (2008): Intervención Psicológica en enfermos de cáncer: planteamientos del presente, deseos del futuro. Análisis y Modificación de Conducta, 34, 259-290.

Ingram, R. \& Price, J. (2001). The role of vulnerability in understanding psychopathology. In: R. Ingram \& J. Price (Ed.), Vulnerability to psychopathology: Risk across the lifespan (pp. 3-19). New York: the Guilford Press.

International Association for Study of Pain. (1994). Classification of chronic pain: descriptions of chronic pain syndromes and definitions of pain terms. ( $2^{\mathrm{a}}$ ed.). Seattle: IASP Press

Jang, K., Thordarson, D., Stein, M., Cohan, S., \& Taylor, S. (2007). Coping styles and personality: a biometric analysis. Anxiety, stress, and coping, 20, 17-24.

Jensen, M., Turner, J., Romano, J., \& Karoly, P. (1991). Coping with chronic pain: a critical review of the literature. Pain, 47, 249-283.

Lamé, I., Peters, M., Vlaeyen, J., Kleef, M., \& Patijn, J. (2005). Quality of life in chronic pain is more associated with beliefs about pain, than with pain intensity. European Journal of Pain, 9, 15-24.

Lauver, S. \& Johnson, J. (1997). The role of neuroticism and social support in older adults with chronic pain behaviour. Personality and Individual Differences, 23, 165-167.

Lazarus, R. \& Folkman S. (1984). Stress, appraisal, and coping. New York: Springer. 
Marrero, R. (2011): Well-being and personality: facetlevel analyses. Personality and Individual Differences, 50, 206-211.

McHorney, C. A., Ware, J. E. Jr., \& Raczek, A. E. (1993). The MOS 36-Item Short-Form Health Survey (SF36): II. Psychometric and clinical tests of validity in measuring physical and mental health constructs. Medical Care, 31, 247-263.

McHorney, C. A., Ware, J. E., Lu, J. F. R., \& Sherbourne, C. D. (1994). The MOS 36-Item Short-Form Health Survey (SF-36): III. Tests of data quality. Scaling assumptions, and reliability across diverse patient groups. Medical Care, 32(1), 40-66.

Merskey, H. \& Bogduk, N. (1994). Classification of Chronic Pain. New York: IASP Press.

Meyer-Rosenberg, K., Burckhardt, C. S., Huizar, K., Kvarnström, A., \& Nord, K. A. (2001): A comparison of the SF-36 and Nottingham Health Profile in patients with chronic neuropathic pain. European Journal of Pain, 5, 391-403.

Monsalve, V., Soriano, J., \& De Andrés, J. (2006). Utilidad del Índice de Lattinen (IL) en la evaluación del dolor crónico: relaciones con afrontamiento y calidad de vida. Revista de la Sociedad Española del Dolor, 13, 216-229.

O'Brien, T. \& DeLongis, A. (1996). The international context of problem-, emotion-, and relationshipfocused coping: the role of the big five personality factors. Journal of Personality, (Special Issue: Personality and Coping), 64, 775-813.

Penley, J. \& Tomaka, J. (2002). Associations among the Big Five, emotional responses, and coping with acute stress. Personality and Individual Differences, $32,1215-1228$.

Phillips, J. \& Gatchel, R. (2000). Extraversionintroversion in chronic pain. In: R. Gatchel \& J. Weisberg (Ed.), Personality characteristics of patients with pain (pp. 181-202). London: British Library.

Ramírez, C., López, A. E., \& Esteve, R. (2004). Personality characteristics as differential variables of the pain experience. Journal of Behavioral Medicine, 27, 147-165.

Schwartz, J., Neale, J., Marco, C., Shiffman, S., \& Stone, A. (1999). Does trait coping exist? A momentary assessment approach to the evaluation of traits. Journal of Personality and Social Psychology, 77, 360-369.

Skodol, A. (2010). The resilient personality. In: Reich, J., Zautra, A. \& Stuart-Hall, J. (Ed.), Handbook of Adult Resilience (pp. 112-125). New York: The guilford Press.

Soriano, J. \& Monsalve, V. (2002). CAD: Cuestionario de Afrontamiento ante el Dolor crónico. Revista de la Sociedad Española del Dolor, 9, 13-22.

Soriano, J. \& Monsalve, V. (2004). Validación del cuestionario de afrontamiento al dolor crónico reducido (CAD-R). Revista de la Sociedad Española del Dolor, 11, 407-414.
Soriano, J. \& Monsalve, V. (2005): El afrontamiento del dolor crónico. Boletín de Psicología, 84, 91-107.

Soriano, J., Monsalve, V., y Gómez-Carretero, P. (2007). Calidad de vida y valoración del dolor: ¿Depende la calidad de vida del tipo de dolor?. Revista de Psicoterapia, 65, 83-93.

Soriano, J., Monsalve, V., Ibáñez, E., y Gómez-Carretero, P. (2010). Personalidad y afrontamiento en dolor crónico neuropático: un divorcio previsible. Psicothema, 22, 537-542.

Soucase, B., Soriano, J., y Monsalve, V. (2005). Influencia de los procesos mediadores en la adaptación al dolor crónico. International Journal of Clinical and Health Psychology, 5, 227-241.

Sriwatanakul, K., Kelvie, L., \& Lasagna, L. (1983). Studies with different types of visual analogue scales for measurement of pain. Clinical Pharmacological Therapy, 34, 234-239.

Suls, J., David, J., \& Harvey, J. (1996). Personality and coping. Three generations research. Journal of Personality, 64, 711-735.

Tugade, M. \& Fredrickson, B. (2004). Resilient individuals use positive emotions to bounce back from negative emotional experiences. Journal of Personality and Social Psychology, 86, 320-333.

Vas, J., Perea, E., Méndez, C., Martín, M., \& Pons, J. (2005). Una búsqueda bibliográfica fallida: ¿qué faltó por buscar? El caso del test de Lattinen. Atención Primaria, 36, 168-170.

Ware, J. E. Jr. \& Sherbourne, C. D. (1992). The MOS 36item short-form health survey (SF-36). I. Conceptual framework and item selection. Medical Care, 30, 473-483.

Weisberg, J. \& Keefe, F. (1999). Personality, individual differences, and psychopathology in chronic pain. In: R. Gatchel \& D. Turk (Ed.), Psychosocial Factors in Pain: Critical Perspectives (pp. 56-73). New York: Guilford. 